\title{
Anxiety as a Personality Trait and Anxiety State, During Coronavirus Covid-19 Pandemic Outbreak among Adult Population
}

\author{
Nita Beluli Luma \\ $\mathrm{PhD}$ (c), Mother Teresa University, North Macedonia
}

\section{Abstract}

The COVID-19 outbreak has warranted a significant influence on our mental health, hence monitoring and following this issue should be a top priority to most of the researchers worldwide. It is essential to protect our mental health and to develop appropriate interventions during this global crisis. Therefore, our study aims to help our population by understanding their emotional, behavioral changes and the overall impact that the fear and insecurity from coronavirus has brought to our lives. The purpose of this study was to investigate the prevalence of anxiety as a state vs. anxiety as a personality trait and factor differences amid coronavirus COVID-19 pandemic outbreak. The survey included 279 respondents, out of which 213 were females and 66 males, age range from 18 to 50 years old. For data collection we have used the 'snowball' sampling technique, which is an online software platform, called Survey Planet. To measure the levels of anxiety we have utilized the STAI state- trait anxiety inventory. To analyze the data we used the SPSS 22.0. Our findings suggest that demographic factors and basic personal data, such as age, marital status, academic level, employment status etc., create the diversity among the population, with the way they experience and how they feel toward this new mental health challenge. With this research we tend to actualize the adult's mental health and to increase the proper weight on the issue by elevating population awareness and attention toward this problem. The world is facing with a new mental health trend, therefore changes in the mental state of every person are worthy of our attention!

Keywords: anxiety, coronavirus anxiety, pandemic outbreak, mental health, anxiety disorder.

\section{Introduction}

The declaration of COVID-19 Pandemic by the World Health Organization on March 11,2020 , brought several impacts for all countries on the planet. To address this serious and exceptional situation, the Government of North Macedonia declared on March 11th the state of alarm to manage the health crisis caused by the COVID-19. 
The lockdown brought not only economic and political issues; it also brought social, emotional, and behavioral impacts.

Regarding the outcomes of researches made worldwide, which have highlighted the increase of family conflicts and the rise of the domestic violence; the increase of number of people that have fallen to extreme poverty due to the economical disruption; the increase of the presence of anxiety and depressive symptoms among people and the worsening of the mental health state of patients with chronic diseases as well; the social distance, employment and many other social and lifestyle changes due to the pandemic outbreak, brought quite a psychological distress and symptoms of mental illness among the population.

Psychologists and mental health professional speculate that the pandemic will affect the mental health of the global population with increasing cases of depression, suicide, and self-injury, apart from other symptoms reported globally for COVID 2019. Closing outlets that sell alcohol also causes symptoms withdrawal and suicide by alcoholics, reported in countries like Kerala in India. They speculate about the possibility of developing neurotic disorders such as generalized anxiety disorder and obsessive-compulsive disorder (OCD) in large population groups. Also related to mood and emotional outburst especially panic, fear, avoidance and fear of meeting others, fear of death (Thanatophobia), fear of isolation, stigmatization, fear of not even getting important items, food, etc., may have psychological manifestations. ${ }^{1}$

Psychosocial stressors related to pandemics include threats to the health of self and loved ones, lockdowns, social distancing, separation from family and friends, death of loved ones, social isolation due to quarantine, shortages of food and medicines, loss of earnings, closure of educational institutions and industries, and cancellation of functions and festivals. ${ }^{23}$

Experience of the recent past tells us that the psychological effects of pandemics are often larger than the medical effects. ${ }^{4}$ Pandemic-related psychosocial stressors may trigger or exacerbate psychiatric disorders, including mood disorders, anxiety disorders, substance use disorders, and posttraumatic stress disorder (PTSD). ${ }^{56}$ Bereave mentor loss of loved ones in the pandemic may be followed by complicated

\footnotetext{
1 Setiati, S., Azwar, M. K. (2020). COVID 19 and Indonesia. Acta medica indonesiana -The Indonesian journal of Internal medicine' Vol 2, N0.1.

2 Taylor, S. (2019). The Psychology of Pandemics. Newcastle Upon Tyne: Cambridge Scholars Publishing. 3 Irwin, M.R., Slavich, G.M. (2017). Psychoneuroimmunology. In:Cacioppo JT, Tassinary LG, Berntson G, editors. Handbook of Psychophysiology. 4th ed.. New York: Cambridge University Press;. p. 377-97. ${ }^{4}$ Wheaton, M.G., Abramowitz, J.S., Berman, N.C., Fabricant, L.E., Olatunji, S.O. (2012) Psychological predictors of anxiety in response to the H I N I (swine flu) pandemic. Cognit Ther Res;36:210-8 5 Shultz, J.M., Baingana, F., Neria, Y. (2015). The 2014 Ebola outbreak and mental health: Current status and recommended response. JAMA; 313:567-8.

6 Wu, K.K., Chan, S.K., Ma, T.M. (2005) Posttraumatic stress, anxiety, and depression in survivors of severe acute respiratory syndrome (SARS). J Trauma Stress ;18:39-42.
} 
grief or a depressive episode. Exposure to widespread mortality, including the deaths of loved ones in the pandemic, may result in PTSD. ${ }^{1}$

Finally, as the pandemic develops, the number of infected people grows; anxiety becomes more evident and increases among the population causing intense fear, insecurity, confusion, social relation issues etc.

\section{Literature Review}

The COVID-19 pandemic found most world populations unprepared, not only in terms of the health threat and demands on the medical system, but also in terms of individuals coping with social distancing measures that disrupted daily routines, limited interpersonal communication, and restricted the availability of social support (Brailovskaia \& Margraf, 2020: Brooks et al., 2020).

Compared to highly structured situations eliciting similar responses in individuals with diverse personality characteristics, this unprecedented and exceptionally uncertain situation may bring about stronger spontaneous reactions of the individual reflecting their enduring dispositional characteristics (Judge \& Zapata, 2015). Anxiety as a trait for instance, can affect in the way of how the individuals experience anxiety as a state, due to the novel coronavirus, or that it may be a trigger to another mental health disturbance, such as depression; or other types of anxiety such as social anxiety, panic disorder and even post traumatic stress disorder, after the novel of coronavirus is over.

Given the current worldwide concern over the spread of the COVID-19, people are faced with several mental health implications. Anxiety is one disorder that is on the top of mental health disturbances during pandemic coronavirus COVID-19, referring to many researches that have been conducted worldwide regarding this mental issue. In Iran, for instance, a survey conducted among college students have come to a conclusion that $35 \%$ of the students experienced moderate to extreme levels of anxiety (Khoshaim, B. K., et al. 2020.) ${ }^{2}$

Some socio-demographic factors are also closely linked with psychological outcomes. For example, it was found that female gender was a risk factor for depressive and anxiety symptoms (Zhou, Zhang et al., 2020). Another factor that puts mental health at risk is the uncertainty about being infected or infecting family and friends further heighten the levels of anxiety (Fiorillo and Gorwood, 2020; Jahanshahi et al, 2020; Maunder et al., 2003; Shigemura et al., 2020).

Economic downfall also seems to affect anxiety and anxiety-related behaviors. Cao et al., (2020) discovered that the report anxiety of college students is associated with

\footnotetext{
${ }^{1}$ Shultz, J.M., Espinel, Z., Flynn, S.W., Hoffmann, Y., Cohen, R.E. (2008). DEEP PREP: All-Hazards Disaster Behavioral Health Training. Miami, FL: DEEP Center.

2 Zhou, Zhang et al., (2020). Prevalence and socio-demographic correlates of psychological health problems in Chinese adolescents during the outbreak of COVID-19. European Child \& Adolescent Psychiatry, 29 (2020), pp. 749-758
} 
parental income as well as place of residence. The debilitating effect of economic downfall was also observed among Japanese citizens in a letter by Shigemura et al. (2020). Fear of the unknown may result to anxiety for those with preexisting mental health concerns and even for those who are psychologically healthy (Cao et al, 2020; Yaoet al., 2020). This is because mental health care may not be prioritized as the world deals with the biological effects of the pandemic (Fiorillo and Gorwood, 2020). ${ }^{1}$

In a relevant study, concerning the mental health and the crisis during the pandemic outbreak, authors have come to a conclusion "The most common mental issues caused by COVID-19 include anxiety, depression, PTSD, and other findings that were generally consistent with severity." 2

Throughout the pandemic, anxiety, depression, sleep disruptions, and thoughts of suicide have increased for many young adults. They have also experienced a number of pandemic-related consequences - such as closures of universities, transitioning to remote work, and loss of income or employment - that may contribute to poor mental health. KFF analysis of the Household Pulse Survey finds that throughout the pandemic, a large share of young adults (ages 18-24) have reported symptoms of anxiety and/or depressive disorder - 56\% as of December 2020 - compared to older adults. $^{3}$

Figure 3

\section{Share of Adults Reporting Symptoms of Anxiety and/or Depressive Disorder During the COVID-19 Pandemic, by Age}

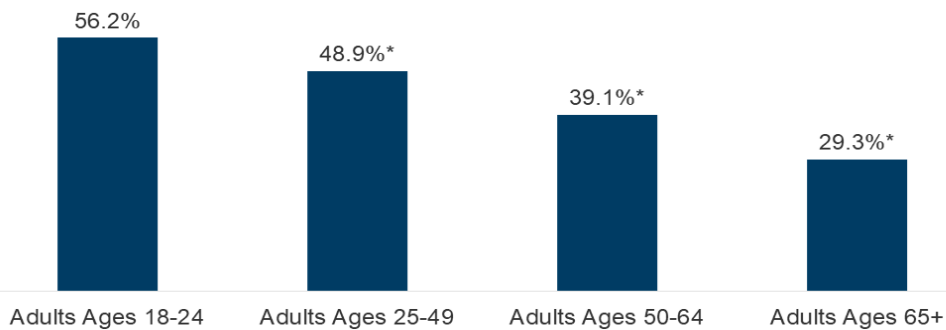

NOTES: xIndicates a statistically significant difference between adults ages 18-24. Data shown includes adults, ages $18+$, with symptoms of anxiety and/or depressive disorder that generally occur more than half the days or nearly every day. Data shown is for December $9-21,2020$. SOURCE: U.S. Census Bureau, Household Pulse Survey, 2020.

\footnotetext{
1 Fiorillo, A., \& Gorwood, P. (2020). The consequences of the COVID-19 pandemic on mental health and implications for clinical practice. European psychiatry : the journal of the Association of European Psychiatrists, 63(1), e32. https://doi.org/10.1192/j.eurpsy.2020.35 ${ }^{2}$ Shamima, A.S., Priyata, D.,et.al. (2020) COVID-19: Embracing MentalHealth Upshot from the Coronavirus Pandemic Crisis. Journal of Psychiatry and Psychiatric Disorders 4. pg 328-342. 3 Panchai, N., Kamal, R., Cox, S., Garfield, R. (February, 2021) The Implications of COVID-19 for Mental Health and Substance Use. KFF. available at: https://www.kff.org/report-section/the-implications-ofcovid-19-for-mental-health-and-substance-use-issue-brief/\#endnote_link_510918-2
} 
Graph.1 Share of adults reporting symptoms of anxiety and/or depressive disorder during COVID-19 pandemic, by age.

Finally we can say that the above mentioned findings from authors and researchers worldwide, regarding the pandemic issue in many aspects and points of view, resulting in different conclusions through analyses of multi dimensional approaches, have given us a head start for the research we were preparing to conduct. The support of these findings have given us a solid ground on what we can lay our hypothesis, and an outline of what to expect from the outcomes of our investigation on mental health, respectively to anxiety as a consequence due to the COVID-19 outbreak and the all the changes that came with it, due to the safety measures that the government set to prevent the further spread of the virus, such as quarantines, setting police hours, social distance and isolation, banning the gatherings etc.

\section{Purpose of research}

The purpose of this study is set to investigate the prevalence of anxiety (as a state vs. anxiety as a personality trait) and impact factor differences amid coronavirus COVID19 pandemic outbreak in the North Macedonia population. With this research we tend to actualize the adult's mental health and to increase the proper weight on the issue by elevating population awareness and researchers attention toward this problem.

The world is facing with a new mental health trend, therefore changes in the mental state of every person is worthy of our attention!

\section{Research tools}

For the investigation of our research we have used the State Trait Anxiety Inventory which was developed by psychologists Charles Spielberg, R.L. Gorsuch, and R.E. Lushene. The STAI measures two types of anxiety - state anxiety, or anxiety about an event, and trait anxiety, or anxiety level as a personal characteristic. The inventory consists of 40 questions on a self-report basis.

The inventory was provided in two languages: English and Albanian language for the respondents.

Study Participants:

We had in total 279 participants from different cities and nationalities around the country. Participant's age was limited between 18 to 50+ years old.

Sampling technique

The Snowball sampling technique was used for collecting information from people around the country. The e-questionnaire was distributed by an Online based platform called Planet Survey. The data was collected online for one week in April, 2020. 


\section{Data analyses}

We analyzed the data with the statistical software (Statistical Package for Social Sciences) version 22.0 which facilitated the process of organizing data into tables, graphics and charts for the sake of better visualization of the results and their interpretation.

\section{Research analyses and results}

The main aim of this study was to examine the correlation among people that experience state anxiety versus trait anxiety.

Descriptive Statistics

\begin{tabular}{|l|l|l|l|}
\hline & Mean & Std. Deviation & N \\
\hline SAT & 58.84 & 13.561 & 281 \\
SAS & 50.56 & 10.107 & 281 \\
\hline
\end{tabular}

Table 1. Descriptive statistics for State Anxiety vs Trait anxiety

Correlations

\begin{tabular}{|ll|l|l|}
\hline & & SAT & SAS \\
\hline SAT & Pearson Correlation & 1 & $.649^{* *}$ \\
& Sig. (2-tailed) & & .000 \\
& $N$ & 281 & 281 \\
\hline SAS & Pearson Correlation & $.649^{* *}$ & 1 \\
& Sig. (2-tailed) & .000 & \\
& $N$ & 281 & 281 \\
\hline
\end{tabular}

**. Correlation is significant at the 0.01 level (2-tailed). Table

2.Pearson correlation for ST anxiety

From the Pearson correlation we have come to a conclusion that we have a statistically significant linear relationship ( $p<=0.01$ ) meaning there is enough evidence to suggest that the correlation we observed does exist in the population. Also the correlation has a high degree $(r=0.65)$ therefore we conclude that the correlation is strong

As we can see in the tables $(1 \& 2)$ the direction of the relationship is positive (i.e., trait anxiety and anxiety as a state are positively correlated $),(\mathrm{P}=0.000)$ meaning that these variables tend to increase or decrease together. (people with higher levels of anxiety trait have a tendency to also experience higher levels of state anxiety and vise versa) .

The second aim of my research study is to verify the anxiety levels in our population assuming that the majority of our population suffers from moderate to high levels of anxiety. Regarding this hypothesis we came to these findings. 


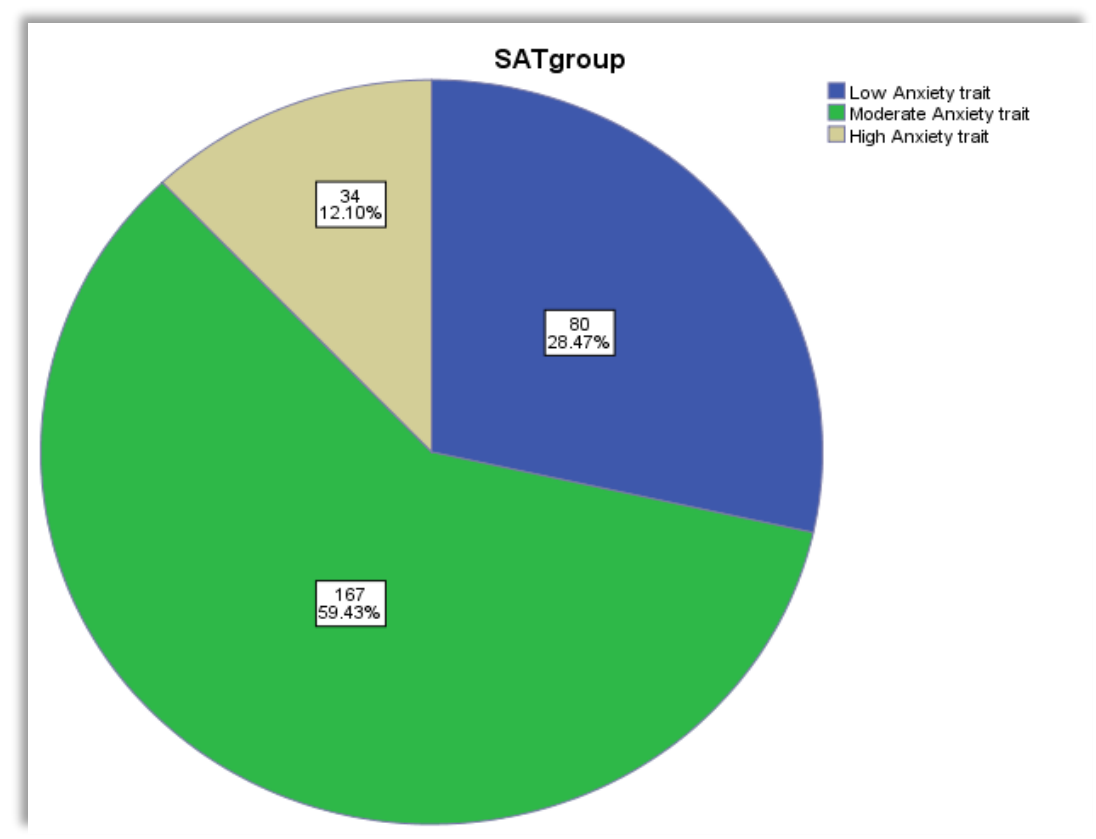

Graph 1. State Anxiety levels in population

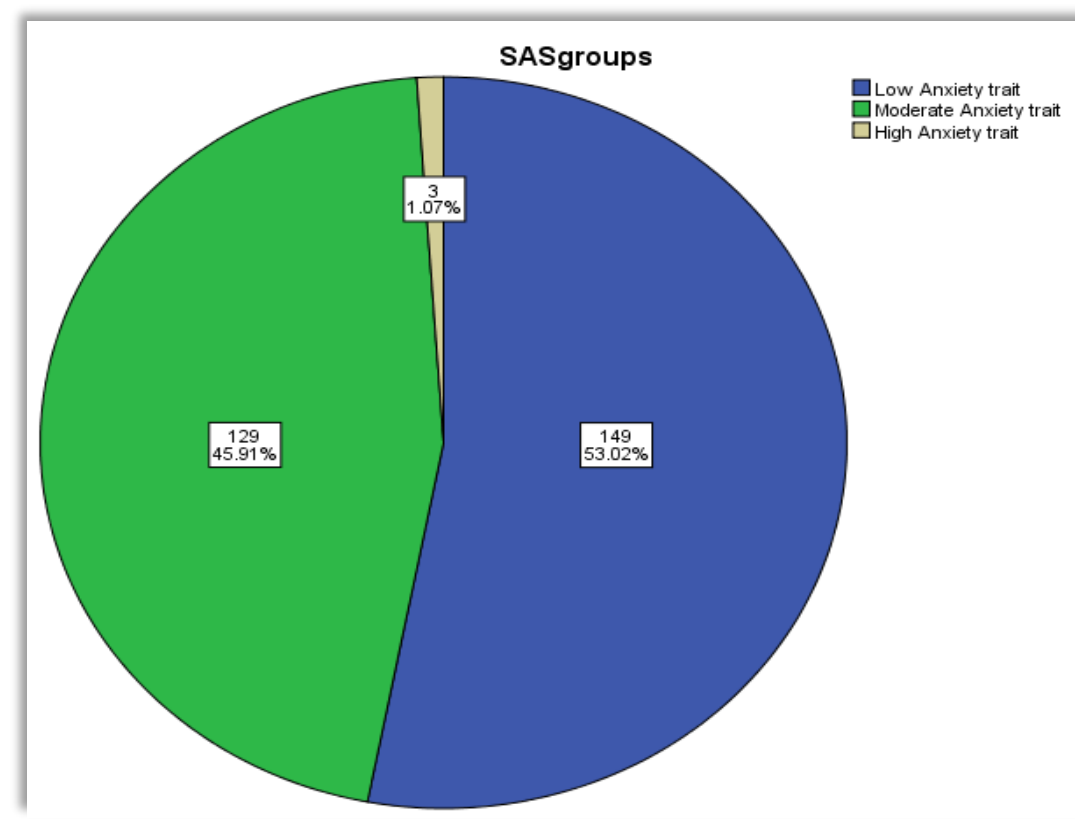

Graph 2. Trait anxiety levels in population

From the graphical representation of data in this pie chart we are looking we can understand right away the thin difference among participants who experience 
anxiety in low level $53 \%$, and moderate level $46 \%$, by leaving behind those who suffer from high levels of anxiety $1 \%$.

We conclude that our findings suggest that the majority of the respondents do not feel anxious about the thread of the novel coronavirus, followed by those who moderately find the thread dangerous for their wellbeing.

From the graphical representation of data in this pie chart we are looking we can visually see that the majority of our respondents have a moderate level of anxiety trait $59.4 \%$, followed by those with low levels of anxiety trait with $28.5 \%$, and the least are those with high levels of anxiety trait represented by $12.1 \%$ of our population.

Our findings suggest that the majority of the people tend to experience a moderate tendency to report and experience negative emotions across many situations.

3. Another objective of our research was to explore the gender differences referring to trait vs state anxiety symptoms. We hypothesized that females tend to suffer more from anxiety as a trait and also as a state in comparison to males but we were able to confirm this hypothesis only for the Trait anxiety where as we can see in the table, where are presented the comparable data with the Anova method, regarding the gender, we will see that the means vary significantly $\mathrm{p}<0.05(\mathrm{~F}=0.08)$ and we conclude that gender differences occur referring Trait anxiety, and fail to prove our hypothesis for the gender differences regarding Anxiety as a state since $\mathrm{F}=0.91$, $\mathrm{p}>0.05$, meaning there is no evidence that the there is gender differences.

\begin{tabular}{|l|l|l|l|l|l|l|} 
ANOVA & $\begin{array}{l}\text { Sum of } \\
\text { Squares }\end{array}$ & $d f$ & Mean Square & F & Sig. \\
\hline SAT & Between Groups & 1284.293 & 1 & 1284.293 & 7.137 & .008 \\
& Within Groups & 50208.817 & 279 & 179.960 & & \\
& Total & 51493.110 & 280 & & & \\
\hline SAS & Between Groups & 1.228 & 1 & 1.228 & .012 & .913 \\
& Within Groups & 28602.053 & 279 & 102.516 & & \\
& Total & 28603.281 & 280 & & & \\
\hline
\end{tabular}

Table 3. Anova method for Anxiety as a trait and as a state - gender differences among respondents

4. Regarding the comparatible means by Anova method to determine the age as a factor in experiencing trait and state anxiety we have come to these conclusions: Middle and early adult agers 30 to 50 years old tend to experience higher levels of anxiety as a trait followed by the group of early adultohood agers, and leaving behind the late middle agers $50+$ years old respondents. 
Surprisingly when it comes to Anxiety as a state due to coronavirus thread, the youngsters are leading with higher points of anxiety followed by the late adult agers and leaving behind the middle agers and early middle agers.

So far if we compare the means we will see that the reached means do not vary very much, and there is no clear evidence that there is a statistical significant difference between the means of the groups of ages and the variables, since $\mathrm{F}=0.37, \mathrm{p}>0.05$ for Trait Anxiety and groups of ages and $\mathrm{F}=0.89, \mathrm{p}>0.05$ for the State Anxiety, meaning that there is no statistical differences among the means.

Descriptives

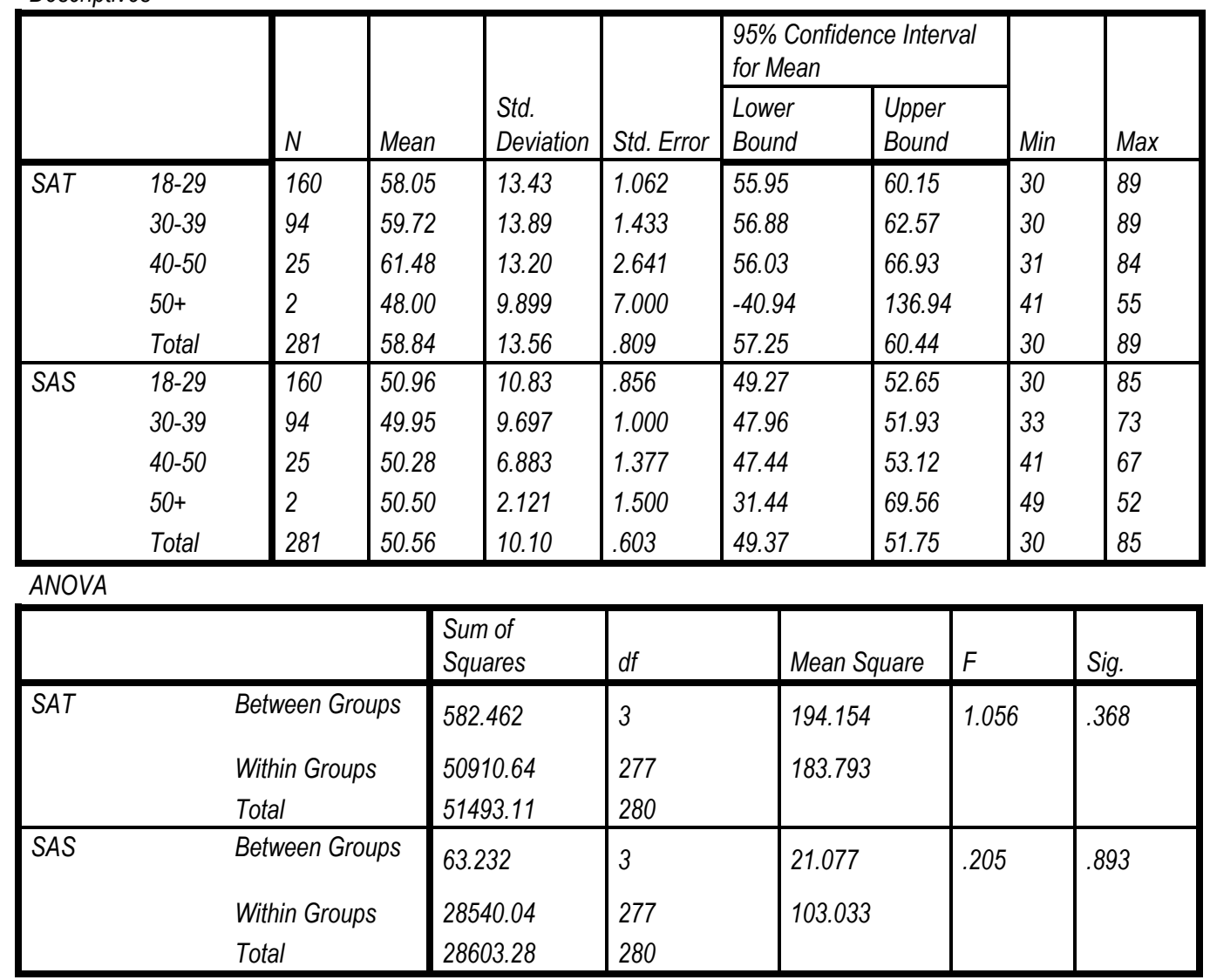

Table 4. Anova method results for age differences among respondents and and State -Trait -anxiety

5. Another objective of our research study was to understand whether the marital status impacts in experiencing state and trait anxiety during the pandemic outbreak.

According to our analyzes through the Anova method we came to a conclusion that there was no difference among the means of the variables, respectively there was no statistically significant difference among the variables of anxiety and marital status 
since $\mathrm{F}=0.25$ for Trait anxiety and $\mathrm{F}=0.95$ for State anxiety, which are $\mathrm{p}>0.05$, meaning that there are no difference between the means and we accept the null hypothesis.

ANOVA

\begin{tabular}{|ll|l|l|l|l|l|}
\hline & $\begin{array}{l}\text { Sum of } \\
\text { Squares }\end{array}$ & Df & Mean Square & F & Sig. \\
\hline SAT & Between Groups & 504.247 & 2 & 252.123 & 1.375 & .255 \\
& Within Groups & 50988.8 & 278 & 183.413 & & \\
& Total & 51493.1 & 280 & & & \\
\hline SAS & Between Groups & 250.390 & 2 & 125.195 & 1.228 & .295 \\
& Within Groups & 28352.8 & 278 & 101.989 & & \\
& Total & 28603.2 & 280 & & & \\
\hline
\end{tabular}

Table 5. Anova method results for marital status and State - Trait anxiety presence

If we look closely to our graphs we would be able to see that slightly higher the Married people have higher levels of trait anxiety, followed by engaged respondents. Single respondents have scored the lowest points in this variable.

Surprisingly quite the opposite happens when we analyze the State anxiety outcomes, where we find the single respondents experiencing higher levels of anxiety due to coronavirus COVID-19, followed by engaged people. The married couples tend to show lower levels of anxiety.

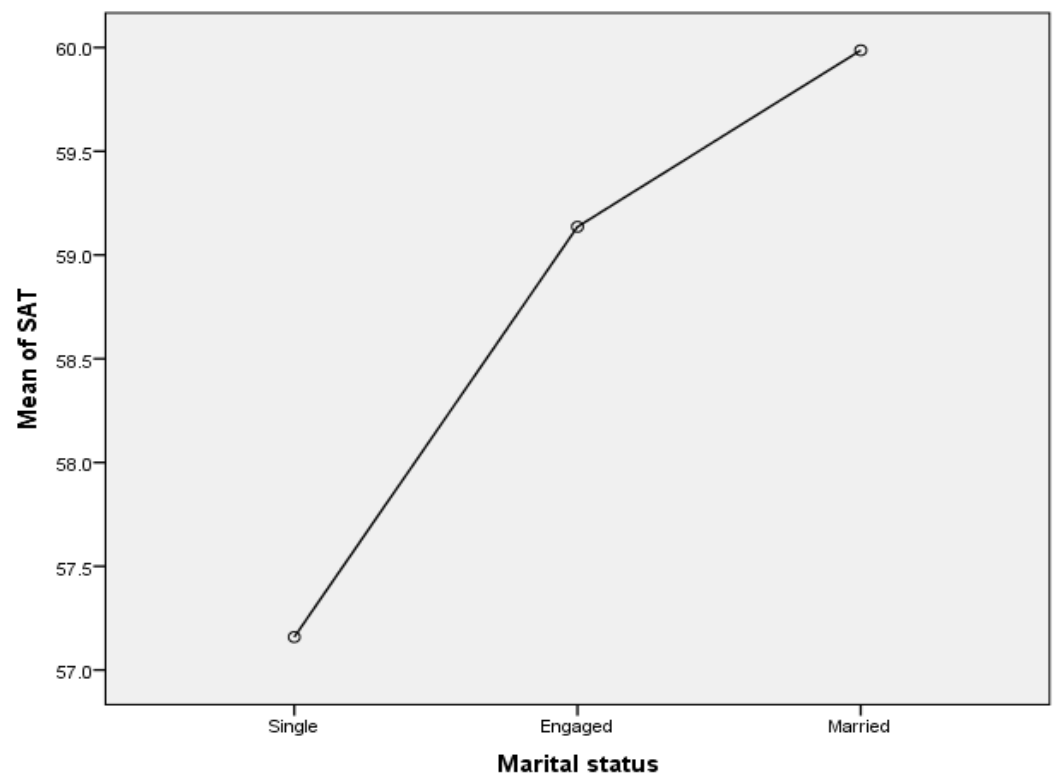

Graph 3. Anxiety as a trait and marital status 


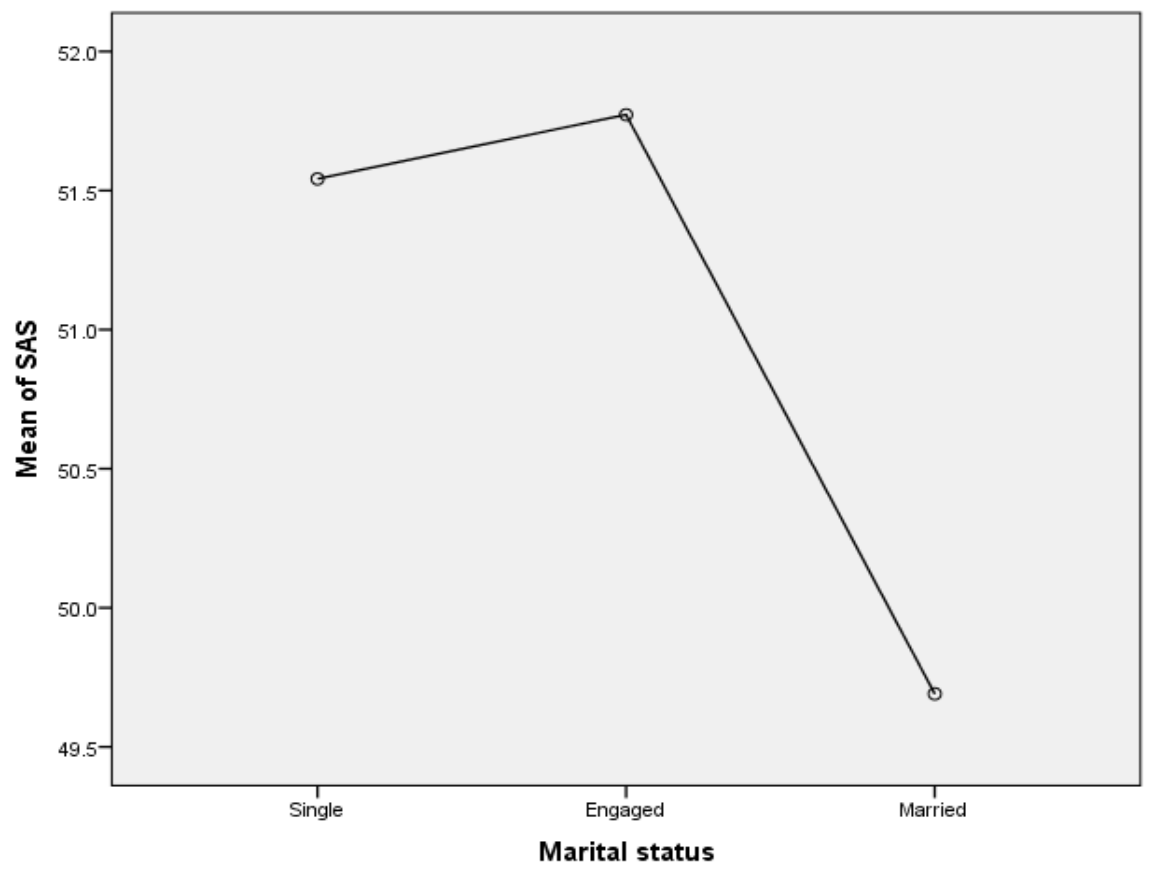

Graph 4. Anxiety as a state and marital status

6. Another purpose of our research study is to understand the employment status as a factor that elicits anxiety due to the pandemic outbreak. Our hypothesis stated that unemployed and employed people experience anxiety as a trait and as a state with no significant difference between them.

According to our findings, we were able to verify our null hypothesis by using the Anova method, as seen in the table for SAT $F=0.307$ and SAS $F=0.102, p>0.05$ meaning that the null hypothesis is accepted and there's no difference between the means of the variables and the employment statuses.

ANOVA

\begin{tabular}{|ll|l|l|l|l|l|}
\hline & Sum of Squares & $d f$ & Mean Square & F & Sig. \\
\hline SAT & Between Groups & 192.343 & 1 & 192.343 & 1.046 & .307 \\
& Within Groups & 51300 & 279 & 183.874 & & \\
& Total & 51493 & 280 & & & \\
\hline SAS & Between Groups & 272.711 & 1 & 272.711 & 2.686 & .102 \\
& Within Groups & 28330 & 279 & 101.543 & & \\
& Total & 28603.1 & 280 & & & \\
\hline
\end{tabular}

Table6. Employment status and State- trait anxiety analysis using ANOVA method 


\begin{tabular}{|ll|l|l|l|l|l|}
\hline & $\begin{array}{l}\text { Sum of } \\
\text { Squares }\end{array}$ & Df & Mean Square & F & Sig. \\
\hline SAS & Between Groups & 574.62 & 3 & 191.542 & 1.893 & .131 \\
& Within Groups & 28028. & 277 & 101.186 & & \\
& Total & 28603. & 280 & & & \\
\hline SAT & Between Groups & 418.37 & 3 & 139.459 & .756 & .519 \\
& Within Groups & 51074. & 277 & 184.385 & & \\
& Total & 51493 & 280 & & & \\
\hline
\end{tabular}

Table 7. Anxiety as a state and as a trait analyses referring respondents educational level

7. The means of the respondents educational level regarding the variables of our study (AS and AT), we can conclude again with the Anova method that the outcomes are greater than the significance level $\mathrm{p}=0.05$ (SAS:F=0.13 and SAT: $\mathrm{F}=0.52$ ) meaning that we can't reject the null hypothesis, meaning that the means have no statistical significant difference.

When we compare the educational level with the anxiety as a trait variable, we see from the graph above that, high schoolers this time point with the lowest trait anxiety score while the $\mathrm{PhD}$ respondents score the highest.

If we look at the graph we may see a detailed view over the slight differences among the variables (Education level and AS) and we see that high schoolers point with the highest scores of anxiety as a state, followed by the other edge of the educational level, the group of respondents with a PhD degree, and leaving behind those with bachelor and master degree as the last.

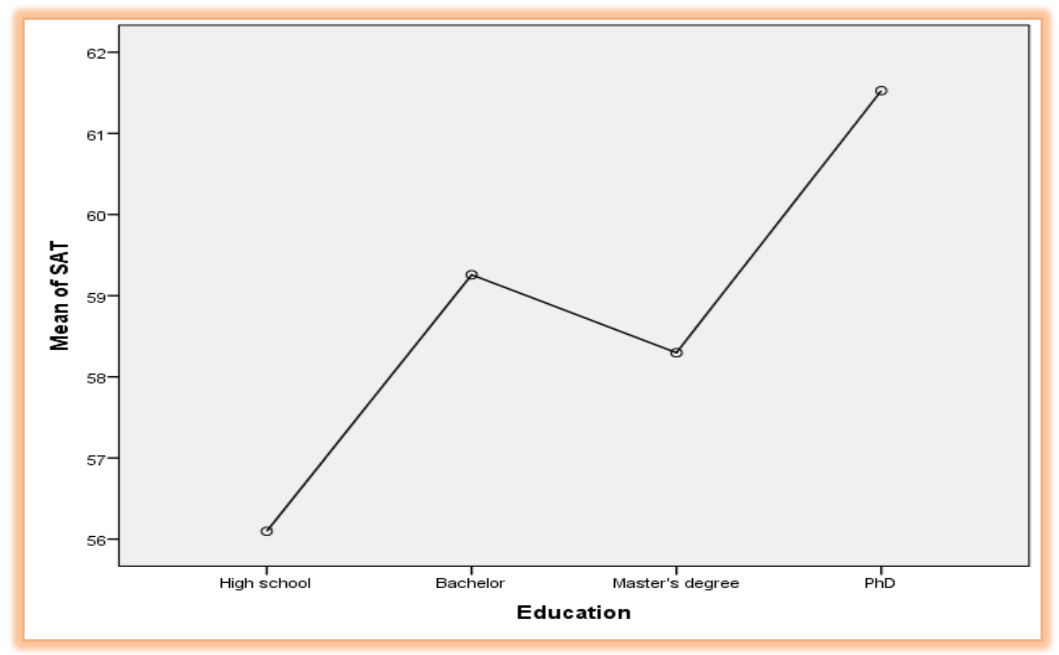

Graph 5. Anxiety trait by respondents' educational level 


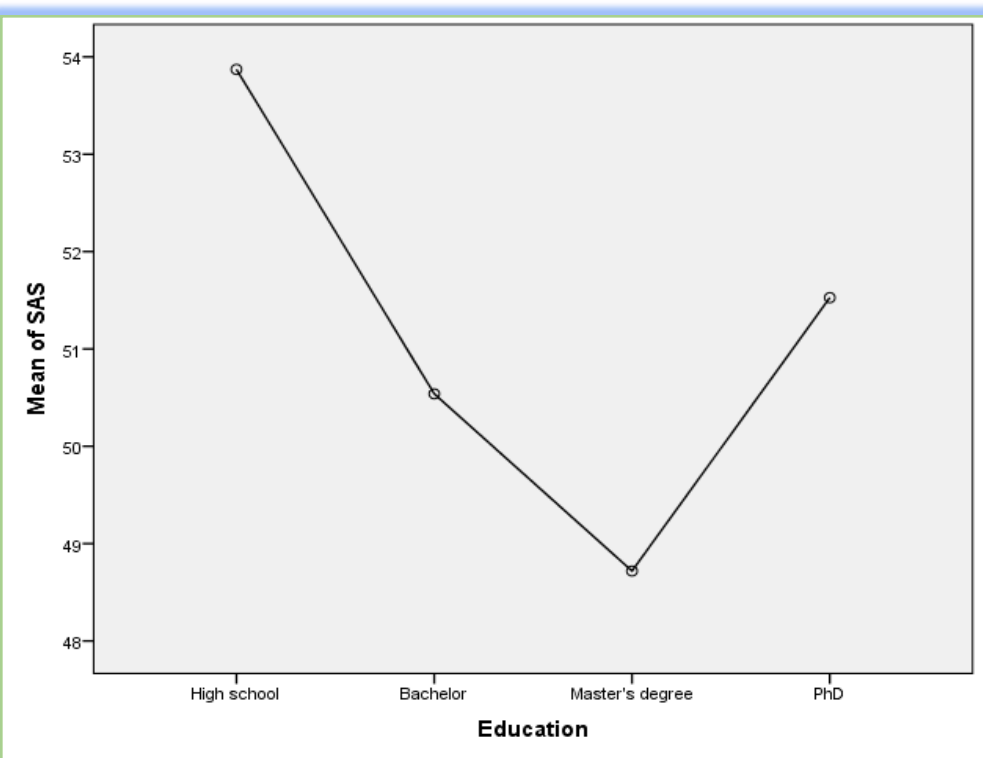

Graph 6. Anxiety State by respondents' educational level

8. Having in consideration the number of cases per city, we do believed that there are significant differences among participants that live in cities with greater number of cases infected by coronavirus, in comparison to those that live in cities with no such history.

\begin{tabular}{|c|c|c|c|c|c|c|c|c|c|}
\hline & & \multirow[b]{2}{*}{$N$} & \multirow[b]{2}{*}{ Mean } & \multirow[b]{2}{*}{ Std. Dev } & \multirow[b]{2}{*}{ Std. Error } & \multicolumn{2}{|c|}{$\begin{array}{l}95 \% \text { Confidence Interval } \\
\text { for Mean }\end{array}$} & \multirow[b]{2}{*}{ Min } & \multirow[b]{2}{*}{ Max } \\
\hline & & & & & & $\begin{array}{l}\text { Lower } \\
\text { Bound }\end{array}$ & $\begin{array}{l}\text { Upper } \\
\text { Bound }\end{array}$ & & \\
\hline \multirow[t]{6}{*}{ SAS } & Sko & 111 & 51.23 & 10.2 & .972 & 49.30 & 53.15 & 33 & 76 \\
\hline & Tet & 81 & 50.15 & 9.47 & 1.052 & 48.05 & 52.24 & 30 & 73 \\
\hline & Str & 25 & 46.48 & 8.10 & 1.621 & 43.13 & 49.83 & 32 & 67 \\
\hline & Gos & 21 & 51.24 & 10.6 & 2.317 & 46.41 & 56.07 & 31 & 73 \\
\hline & Other & 43 & 51.65 & 11.4 & 1.750 & 48.12 & 55.18 & 32 & 85 \\
\hline & Total & 281 & 50.56 & 10.1 & .603 & 49.37 & 51.75 & 30 & 85 \\
\hline \multirow[t]{6}{*}{ SAT } & Sko & 111 & 57.38 & 13.3 & 1.264 & 54.87 & 59.88 & 30 & 89 \\
\hline & Tet & 81 & 60.65 & 13.5 & 1.501 & 57.67 & 63.64 & 30 & 89 \\
\hline & Str & 25 & 56.76 & 12.8 & 2.567 & 51.46 & 62.06 & 32 & 73 \\
\hline & Gos & 21 & 61.43 & 16.8 & 3.677 & 53.76 & 69.10 & 31 & 89 \\
\hline & Other & 43 & 59.16 & 12.9 & 1.970 & 55.19 & 63.14 & 32 & 88 \\
\hline & Total & 281 & 58.84 & 13.5 & .809 & 57.25 & 60.44 & 30 & 89 \\
\hline
\end{tabular}


ANOVA

\begin{tabular}{|ll|l|l|l|l|l|}
\hline & Sum of Squares & Df & Mean Square & F & Sig. \\
\hline SAS & Between Groups & 539.873 & 4 & 134.968 & 1.327 & .260 \\
& Within Groups & 28063.409 & 276 & 101.679 & & \\
& Total & 28603.281 & 280 & & & \\
\hline SAT & Between Groups & 757.118 & 4 & 189.279 & 1.030 & .392 \\
& Within Groups & 50735.992 & 276 & 183.826 & & \\
& Total & 51493.110 & 280 & & & \\
\hline
\end{tabular}

Table 8. State-Trait Anxiety analyses of the respondents regarding their hometowns

Referring to the tables above, which compare the means of respondents responds coming from different cities across North Macedonia and the variables we conclude that the means are not statistically different, since the results $\mathrm{F}=0.26$ and $\mathrm{F}=0.39$ are greater than the significance level $p=0.05$, therefore we state that we can't reject the null hypothesis.

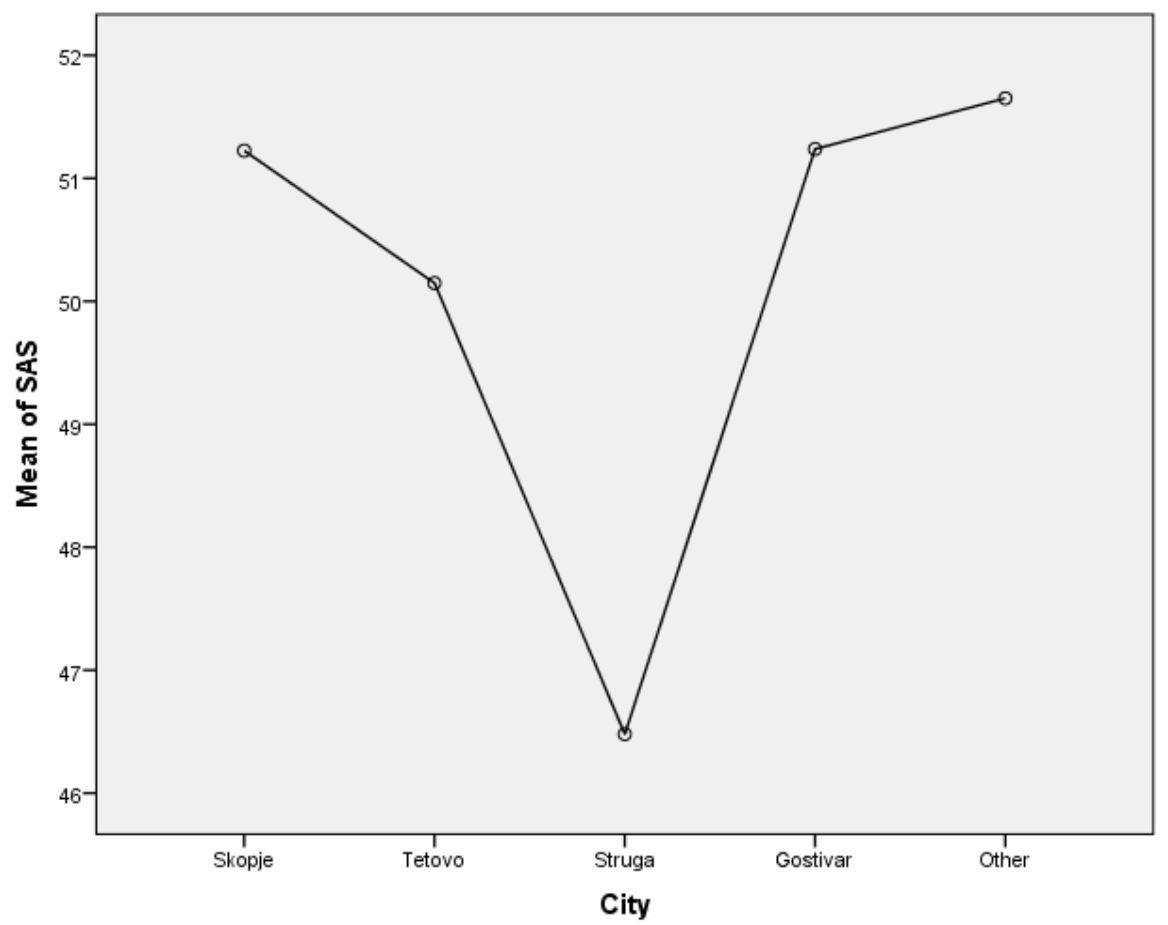

Graph7. Respondents' hometown and state anxiety data 


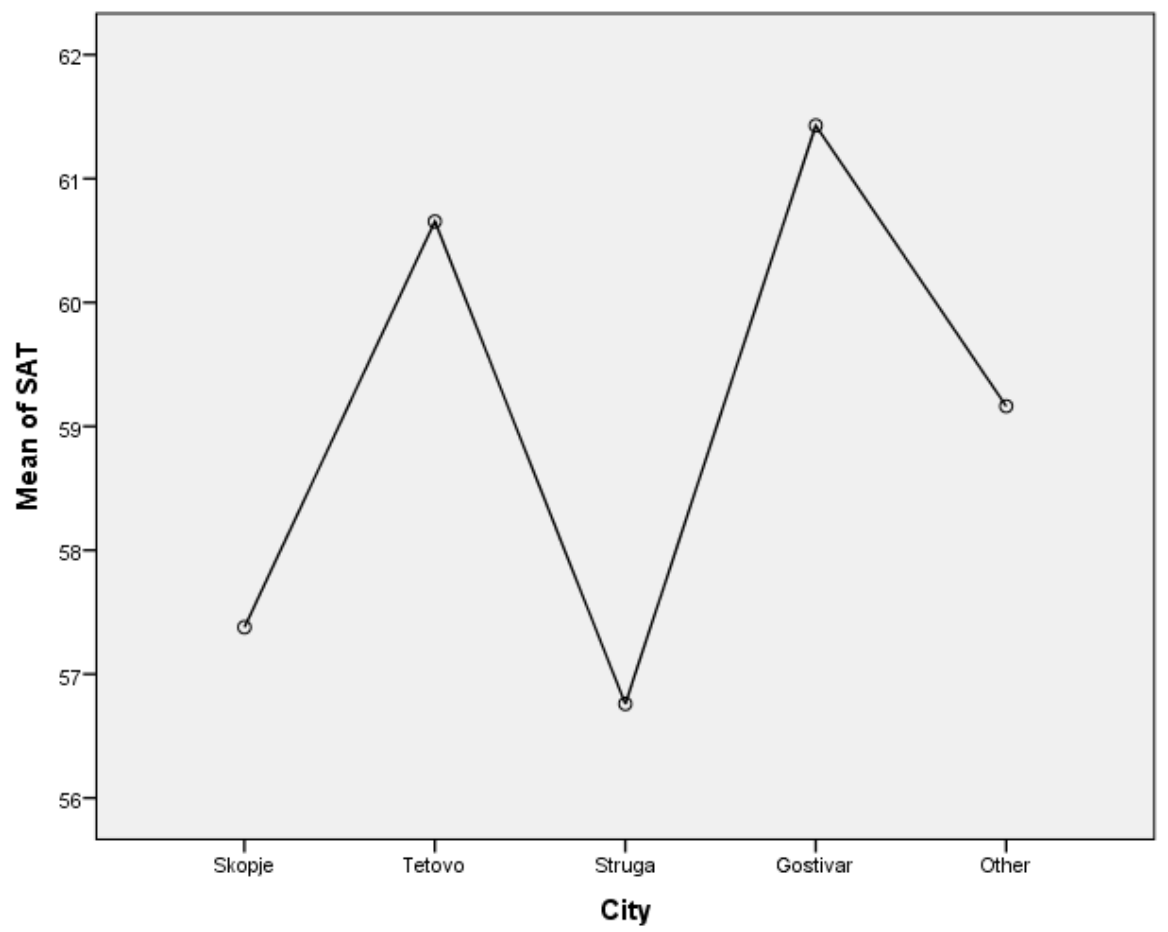

Graph 8. Respondents' hometown and trait anxiety data

By looking at the graphs we can see that the respondents coming from Struga are those with lower levels of anxiety in both categories. We notice high levels of anxiety in the participants coming from Gostivar, in both categories, and leading in the state anxiety. Tetovo also shows moderately the presence of anxiety levels in both categories, leaving Skopje respondents and from other cities, in between.

\section{Conclusion and Future Recommendations}

Referring to our data analyses we were able to come to the conclusion that there is a significant strong positive correlation among people that experience state anxiety and those who suffer from trait anxiety, meaning that those individuals that suffer from one type of anxiety, do also experience the other one as well.

Our findings suggest that the majority of the respondents do not feel anxious about the thread of the novel coronavirus, followed by those who moderately find the thread dangerous for their wellbeing (see Graph 1.). On the other hand, when data were analyzed for trait anxiety, the majority of our respondents resulted to experience a moderate level of anxiety. Comparing these two types of anxiety and their presence in our population by percentage, we can conclude that in our population, trait anxiety is more visible or present as a personality trait, than state anxiety as a state, due to the pandemic outbreak. 
Through this research we couldn't find any gender differences when regarding the state anxiety due to pandemic outbreak, but we could prove that females exceed males on their tendency to report fears, worries and anxiety across many situations (trait anxiety).

We didn't find any statistical difference among the means of our respondents when we compared the ST-Anxiety and their age groups, meaning that there is no evidence that older people experience higher levels of anxiety in comparison to youngsters. (see table 4.)

Also we didn't find a statistical significant difference among the variables of anxiety and the marital status, therefore we conclude that marital status hasn't proved to be a crucial factor related to anxiety during the pandemic outbreak.

We were able to come to a conclusion that there is no difference when it comes to the tendency to experience and feel negative emotions, between employed and unemployed people, during coronavirus outbreak, since the employed are frustrated having to contact with many people during the day and on the other hand the unemployed struggle with their survival.

Respondents educational level regarding the variables of our study, haven't shown a significant statistical difference, meaning that education level is not a factor that influences how one's cope with anxiety on pandemic times.

And the last finding of this study is that respondents' hometowns don't play a role on the state or trait anxiety levels, no matter if their city counts the highest or the lowest number of coronavirus infected people in the country. Respondents from city of Struga show lowest levels of anxiety in both types, and the majority of the highest levels of anxiety, in city of Gostivar (see graph $7 \& 8$ ).

\section{Recommendations for Future Researchers}

In our survey we have emphasized the desire to understand two aspects of anxiety in the pandemic times, involving adults only in the research process. We are aware that doing this we missed data findings involving teenagers and old adults, therefore we recommend that future researchers in the same topic, would want to analyze anxiety in other stages of life. Having the data compared between early adulthood participants and middle age adults, we think that we might have had different results of anxiety range if we planned elderly people to be participants of this survey.

Including an alternative a.c.a intervening variable would have been preferred in order to distinguish female and male participant's anxiety sources or their connection. For instance if the pandemic outbreak is the independent variable, and anxiety as a state vs trait are the dependent variables, that the intervening variable might have been: family (financial) incomes; access to quality healthcare; nutrition; sleep habits etc., that could have linked pandemic outbreak with anxiety.We do believe that even 
though we didn't find any relevant gender differences between them, if we had an intervening variable we would have been able to achieve that difference.

For data gathering we have used the software Survey Planet in order to design and share our survey online, because sharing it on paper during the pandemic with the restriction measures was quite difficult, but the disadvantage of this way of gathering data is that we can't really tell how likely the participant is engaged in answering the items; do older people know how to respond to online surveys ; lack of the interviewer to clarify the items can lead to less reliable data, therefore doing a combination of two survey modes: paper and online questionnaires would give us a whole new perspective of the current issue.

\section{References}

[1] Zhou, Zhang et al., (2020). Prevalence and socio-demographic correlates of psychological health problems in Chinese adolescents during the outbreak of COVID-19. European Child \& Adolescent Psychiatry, 29 (2020), pp. 749-758

[2] Al-Gelban, K. S., Al-Amri, H.S., Mostafa, O. A. (2009) Prevalence of depression, anxiety and stress as measured by the depression, anxiety, and stress scale (DASS-42) among secondary school girls in Abha, Saudi Arabia. Sultan Qaboos Univ Med J. 9:140-7.

[3] Al-Gelban, K. S. (2007). Depression, anxiety and stress among Saudi adolescent school boys.J $R$ Soc Promot Health. 127:33-7. doi: $10.1177 / 1466424007070492$

[4] Alyami, H. S., Naser, A.Y., Dahmash, E.Z., Alyami, M.H., Al-Meanazel, O.T., AlMeanazel, A.T. Depression and anxiety during 2019 coronavirus disease pandemic in Saudi Arabia: a cross-sectional study. medRxiv [Preprint]. (2020). doi: 10.1101/2020.05.09.20096677

[5] Kumar, A., \& Rajasekharan, N. (2020): COVID 19 and its mental health consequences, Journal of Mental Health, retrieved from: https://doi.org/10.1080/09638237.2020.1757052

[6] Corbett, G.A., Milne S.J., Hehir, M.P., Lindow, S.W., O'connell, M.P. (2020). Health anxiety and behavioural changes of pregnant women duringthe COVID19 pandemic. European Journal of Obstetrics, Gynecology, and Reproductive Biology. 24 (1). 312-323

[7] Czeisler, M.É., Lane, R.I., Petrosky, E., et al. (June 24-30, 2020) Mental Health, Substance Use, and Suicidal Ideation During the COVID-19 Pandemic — United States. MMWR Morb Mortal Wkly Rep. 2020;69:1049-1057.

[8] Dong, L., Bouey, J. (2020). Public mental health crisis during COVID-19 Pandemic, China Emerging Infectious diseases.Vol.26 (7),1616-1618. retrieved from: https://dx.doi.org/10.3201/eid2607.200407.

[9] Dunstan, D.A., Scott, N., Todd, A.K. (2017) Screening for anxiety and depression: reassessing the utility of the Zung scales. BMC Psychiatry. 17:329. doi: 10.1186/s12888-017-1489-6 
[10] González, S. C., Ausín, B., Castellanos, M.Á., et al. (2020) Mental health consequences during the initial stage of the 2020 Coronavirus pandemic (COVID-19) in Spain. Brain Behav Immun. 87 (1):172-176.

[11] Hossain, I., Mullick, A.R., Haidar,A. and Aktaruzzaman, M.M. (2019). The COVID-19 pandemic and mental health-A systemic review. (pp. 1-4).

[12] Irwin, M.R., Slavich, G.M. (2017). Psychoneuroimmunology. Handbook of Psychophysiology. 4th ed. New York: Cambridge University Press; p. 377-97.

[13] Liang, L., Gao, T., Ren, H. et al. (2020). Post-traumatic stress disorder and psychological distress in Chinese youths following the COVID-19 emergency. J Health Psychol. 25(9):1164-1175.

[14] Loiwal, M. (2020). 20\% increase in patients with mental illness since coronavirus outbreak: Survey. India Today. Retrieved from: https://www.indiatoday.in/india/story/20-per-cent-increase-in-patientswith-mental-illness-since-coronavirus-outbreak-survey-1661584-2020-0331

[15] Moukaddam, N., Shah, A. (2020). Psychiatrists beware! The impact of COVID19 and pandemics on mental health. Psychiatric Times, 37 (3). retrieved from: https://www.psychiatrictimes.com/psychiatrists-beware-impactcoronavirus-pandemics-mental-health

[16] Rajkumar, R.P. (2020) COVID-19 and mental health: A review of the existing literature. Asian journal psychiatry, Vol 52, p.102066.

[17] Shultz, J.M., Baingana, F., Neria, Y. (2015). The 2014 Ebola outbreak and mental health: Current status and recommended response. JAMA; 313:567-8.

[18] Shultz, J.M., Espinel, Z., Flynn, S. W., Hoffmann, Y., Cohen, R. E. (2008). DEEP PREP: All-Hazards Disaster Behavioral Health Training. Miami, FL: DEEP Center.

[19] Taylo, R. S. (2019). The Psychology of Pandemics. Newcastle Upon Tyne: Cambridge Scholars Publishing.

[20] Wheaton, M. G., Abramowitz, J.S., Berman, N. C., Fabricant, L. E., Olatunji, S.O. (2012) Psychological predictors of anxiety in response to the H I N I (swine flu) pandemic. Cognit Ther Res;36:210-8

[21] World Health Organization. (2020). Mental health and psychosocial considerations during the COVID - 19 Outbreak. available at: https://www.who.int/docs/default-source/coronaviruse/mental-healthconsiderations.pdf

[22] World Health Organization. (2020). Mental health and psychosocial consideration during the COVID-19 outbreak. WHO regerence number: WHO/2019-nCoV/MentalHealth/2020.1 retrieved from: https://www.who.int/docs/default-source/coronaviruse/mental-healthconsiderations.pdf

[23] Wu, K. K., Chan, S.K., Ma, T.M. (2005) Posttraumatic stress, anxiety, and depression in survivors of severe acute respiratory syndrome (SARS). J Trauma Stress ;18:39-42. 
[24] Wang, C., Pan, R., Wan, X., Tan, Y., Xu, L., Ho, C. S. (2020). Immediate psychological responses and associated factors during the initial stage of the 2019 coronavirus disease (COVID-19) epidemic among the general population in China. International Journal of Environmental Research and Public Health, 17, 1729. https://doi.org/10.3390/ijerph17051729

[25] Xiao, C. (2020) A novel approach of consultation on 2019 novel coronavirus (COVID-19)-related psychological and mental problems: structured letter therapy. Psychiatry Investig. 17:175-6. doi: 10.30773/pi.2020.0047

[26] Yang, Y., Li, W., Zhang, Q., Zhang, L., Cheung, T., Xiang, Y. T. (2020) Mental health services for older adults in China during the COVID-19 outbreak. Lancet Psychiatry. 7:22. doi: 10.1016/S2215-0366(20)30079-1 